\title{
Natural oil blend formulation as an anti-African swine fever virus agent in in vitro primary porcine alveolar macrophage culture
}

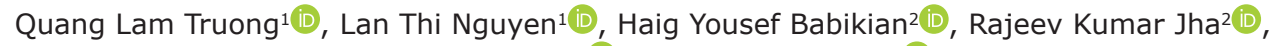 \\ Hoa Thi Nguyen ${ }^{1}$ a and Thanh Long To ${ }^{1}$ iD
}

1. Key Laboratory of Veterinary Biotechnology, Faculty of Veterinary Medicine, Vietnam National University of Agriculture, Hanoi, Vietnam; 2. Department of Research and Development, PT. Rhea Natural Sciences, Jakarta, Indonesia.

Corresponding author: Haig Yousef Babikian, e-mail: haig.babikian@cpp.co.id

Co-authors: QLT: tqlam@vnua.edu.vn, LTN: nguyenlan@vnua.edu.vn, RKJ: rajeev.kumar@cpp.co.id, HTN: hoanguyen2405@gmail.com, TLT: tolongthanh@gmail.com

Received: 17-11-2020, Accepted: 08-02-2021, Published online: 30-03-2021

doi: www.doi.org/10.14202/vetworld.2021.794-802 How to cite this article: Truong QL, Nguyen LT, Babikian HY, Jha RK, Nguyen HT, To TL (2021) Natural oil blend formulation as an anti- African swine fever virus agent in in vitro primary porcine alveolar macrophages culture, Veterinary World, 14(3): 794-802.

\begin{abstract}
Background and Aim: African swine fever is one of the severe pathogens of swine. It has a significant impact on production and economics. So far, there are no known remedies, such as vaccines or drugs, reported working successfully. In the present study, the natural oil blend formulation's (NOBF) efficacy was evaluated against ASFV in vitro using porcine alveolar macrophages (PAMs) cells of swine.

Materials and Methods: The capacity of NOBF against the ASFV was tested in vitro. The NOBF combines Eucalyptus globulus, Pinus sylvestris, and Lavandula latifolia. We used a 2 -fold serial dilution to test the NOBF formulation dose, that is, $10^{5} \mathrm{HAD} 50 / \mathrm{mL}$, against purified lethal dose of African swine in primary PAMs cells of swine. The PAM cells survival, real-time polymerase chain reaction (PCR) test, and hemadsorption (HAD) observation were performed to check the NOBF efficacy against ASFV.

Results: The in vitro trial results demonstrated that NOBF up to dilution 13 or $0.000625 \mathrm{~mL}$ deactivates the lethal dose $10^{5}$ HAD50 of ASFV. There was no HAD (Rosetta formation) up to dilution 12 or $0.00125 \mathrm{~mL}$ of NOBF. The Ct value obtained by running real-time PCR of the NOBF group at $96 \mathrm{~h}$ post-infection was the same as the initial value or lower (25), whereas the $\mathrm{Ct}$ value of positive controls increased several folds (17.84).
\end{abstract}

Conclusion: The in vitro trial demonstrated that NOBF could deactivate the ASFV. The NOBF has the potential to act as anti-ASFV agent in the field. The next step is to conduct in vivo level trial to determine its efficacy.

Keywords: African swine fever virus, in vitro trials, natural oil blend formulation, primary porcine alveolar macrophages cells.

\section{Introduction}

African swine fever virus (ASFV) reported as deadly for pigs. It is listed as a "notifiable disease" by the OIE due to high illness rates and a high mortality rate, up to $100 \%$, and substantial financial losses [1-3]. Further spread of ASF to China has had disastrous consequences, especially instead of the fact that China contains more than half of the world's pig population [4]. To date, as far as Vietnam is concerned, ASF has appeared in all 63 provinces of Vietnam, has destroyed more than 5.6 million pigs (more than $20 \%$ of total pigs), has decreased pork production by $8.3 \%$, and has affected mainly smallscale farms [5-8].

The typical signs and symptoms of ASF are high fever, decreased appetite and weakness, difficulty

Copyright: Truong, et al. Open Access. This article is distributed under the terms of the Creative Commons Attribution 4.0 International License (http://creativecommons.org/licenses/by/4.0/), which permits unrestricted use, distribution, and reproduction in any medium, provided you give appropriate credit to the original author(s) and the source, provide a link to the Creative Commons license, and indicate if changes were made. The Creative Commons Public Domain Dedication waiver (http://creativecommons.org/ publicdomain/zero/1.0/) applies to the data made available in this article, unless otherwise stated. in standing, red or blue blotches on the skin (particularly around ears and snout), and, especially in sows, the symptoms of miscarriage, stillbirths, and weak litters can occur $[9,10]$. Like, diarrhea, vomiting, and difficulty breathing or coughing, the symptoms can also occur with the disease [9]. ASFV is a large, enveloped and structurally complex DNA virus with the Asfarviridae family's icosahedral morphology. The virus can persist for a long time in the environment, carcasses, and various swine products. The vectors and carriers of the ASF virus are warthogs (Phacochoerus africanus), bush pigs (Potamochoerus porcus and Potamochoerus larvatus), and soft ticks (Ornithodoros moubata) [4] in which the virus is transmitted trans-staidly and through transovarial routes [9].

The role of natural oils as antiviral components is well known. As a standardized compound, natural products are significant components with antiviral properties [11]. A formulation was developed by blending three natural oils, Eucalyptus globulus, Pinus sylvestris, and Lavandula latifolia, with antiviral properties. Cineole, the significant component of eucalyptus oil, has potent anti-inflammatory and 
anti-microbial properties [12]. Cineole is well known to treat the respiratory tract's primary viral infections $[13,14]$. Linalool, a significant lavender oil component, has shown antiviral activities [15-17]. Isobornyl acetate extracted from pine oil has anti-microbial properties [14].

In the present study, the natural oil blend formulation's (NOBF) efficacy was evaluated against ASFV using porcine alveolar macrophage (PAM) cells of swine in an in vitro medium.

\section{Materials and Methods}

Ethical approval

The protocols for pig euthanization and lung collection for isolation of primary PAM cells from healthy pigs and in vitro study were approved by the Animal Welfare and Ethics Committee of Vietnam National University of Agriculture, Vietnam.

\section{Study location and period}

In this trial, we selected 7-10-week-old healthy pigs negative for ASFV, PCV2, CSFV, PRRSV, and negative for ASFV Ab for isolation of PAM cells. The animals were housed and used in an isolated area in the Biosecurity Animal Facility Centre of the Vietnam National University of Agriculture (VNUA), Hanoi, Vietnam. The study was conducted from October 2019 to January 2020.

\section{NOBF development}

A formulation was developed by mixing an essential oil blend using three oils, E. globulus, P. sylvestris, and L. latifolia, in a determined concentration. The oils, E. globulus, P. sylvestris, and L. latifolia, obtained from the vendors who comply with the strictest industry practices: Demeter Agro Research and Improvements Pty Ltd., Australia, New Directions Australia Pty Ltd., Australia, and Australian Botanical Products Pty Ltd, Australia. Each natural oil is obtained through the steam distillation process and should undergo thorough checking for the quality and chemical compositions based on European Pharmacopeia. After the natural oils are declared to pass the quality checking, the mixture of the NOBF conducted with the following sequence and percentage: E. globulus, P. sylvestris, and L. latifolia are added in equal quantities to form the NOBF.

We followed a 2 -fold dilution procedure to obtain the optimum dose of the application. The NOBF was serially diluted from $2.5 \mathrm{~mL}$ to $0.000078 \mathrm{~mL}$ (dilution 1 to dilution 16) to perform the in vitro trials.

\section{Toxicity test of NOBF}

The formulation was pre-tested on animals for toxicity and tolerance level. The toxicity level of NOBF was tested at two levels. The first level test was performed in the PAM cells, whereas the tolerance level of NOBF was tested in live pigs. The NOBF in 16 double-fold dilutions of $2.5 \mathrm{~mL}-0.000078 \mathrm{~mL}$ was mixed with the PAM cells and the ASFV. The cell viability was tested under a microscope at every $24 \mathrm{~h}$ interval.

\section{Active ingredient identification in NOBF}

The gas chromatography technique was used to extract and identify the active ingredients with anti-ASFV properties. Gas Agilent 6890 and 7890 Gas Chromatography-Flame Ionization Detector Shimadzu GC 2014 analysis was conducted at the Faculty of Pharmacy Laboratory at the University of Indonesia. The details of the standards used in this analysis are as follows:

a) Standard 1,8-Cineole

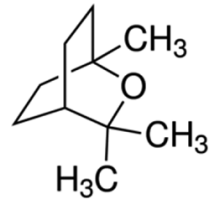

Formula: $\mathrm{C}_{10} \mathrm{H}_{18} \mathrm{O}$

Molecular weight: $154.25 \mathrm{~g} / \mathrm{mol}$

CAS-No.: 470-82-6

Product number: C80601

Brand: Sigma-Aldrich, USA

\section{b) Standard linalool}<smiles>C=CC(C)(O)CCC=C(C)C</smiles>

Formula: $\mathrm{C}_{10} \mathrm{H}_{18} \mathrm{O}$

Molecular weight: $154.25 \mathrm{~g} / \mathrm{mol}$

CAS-No.: 126-91-0

EC-No.: 204-811-2

Product NUMBER: 74856

Brand: Sigma-Aldrich

\section{c) Standard isobornyl acetate}

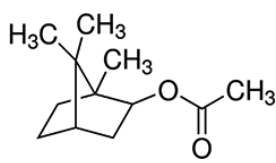

Formula: $\mathrm{C}_{12} \mathrm{H}_{20} \mathrm{O}_{2}$

Molecular weight: $196.29 \mathrm{~g} / \mathrm{mol}$

CAS-No.: 125-12-2

EC-No.: 204-727-6

Product number: W216003

Brand: Sigma-Aldrich

\section{Primary PAM cells}

Our team collected the primary PAMs from 7-week-old healthy pigs (negative for ASFV, PCV2, CSFV, and PRRSV). We maintained the cells in the growth medium, including an RPMI 1640 medium (Gibco, USA) supplemented with $10 \%$ fetal calf serum (FCS; Gibco) and 1\% penicillin-streptomycin solution (Gibco) at $37^{\circ} \mathrm{C}$ with $5 \% \mathrm{CO}_{2}$. We also prepared red blood cells from EDTA-treated swine blood using Percoll (GE Healthcare, USA) and kept it in an RPMI 1640 medium (Gibco), 1\% penicillin-streptomycin solution, and maintained it at $4^{\circ} \mathrm{C}$ until use.

\section{ASFV preparation}

The VNUA-ASFV-L01/HN/04/19 virus strain was isolated from a pig with apparent symptoms in 
Thai Binh Province, Vietnam. The virus strain was purified and quantified in the molecular biology laboratory of VNUA, Vietnam. The lethal and sublethal doses were optimized in the controlled conditions. The ASFV strain VNUA01/04.2019 was adapted to grow in PAMs and further passaged in PAMs. The stock used in the present study was obtained after the $15^{\text {th }}$ passage. Briefly, the PAMs were infected at a multiplicity of infection of 0.1 with VNUA-ASFV-L01/ HN/04/19 in the growth medium, including an RPMI 1640 medium supplemented with $10 \%$ FCS and 1\% penicillin-streptomycin solution. We added to each well the maintenance medium containing an RPMI 1640 medium supplemented with 5\% FCS, $1 \%$ penicillin-streptomycin solution, and 2\% suspension of red blood cells. The team performed the ASFV titration on the PAMs cultures in 96-well plates. The presence of ASFV was assessed by hemadsorption (HAD). The observation of HAD was for 5 days, and the calculation of $50 \%$ HAD observation (HAD50) was performed using the method described by Reed et al. [18] and King et al. [19].

\section{Antiviral activity of NOBF using an in vitro medium}

PAMs were grown on 48-well tissue culture plates using a growth medium, including an RPMI 1640 medium supplemented with $10 \%$ FCS and 1\% penicillin-streptomycin solution. The NOBF was serially 2-fold diluted (Table-1) in a warmed RPMI 1640 to prepare the working stocks after $3 \mathrm{~h}$ of incubation of serially 2-fold diluted NOBF with VNUA-ASFV-L01/ $\mathrm{HN} / 05 / 19$.

The ASF virus dose $10^{5}$ HAD50 in the ratio of $1: 1$, duplicate cultures were infected with the corresponding virus in a diluted volume of a medium containing the NOBF at $37^{\circ} \mathrm{C}$ in an atmosphere of $5 \%$ $\mathrm{CO}_{2}$ for $1 \mathrm{~h}$ (Table-1 and Figure-1). The culture was added to the maintenance medium and incubated until a massive cytopathic effect, such as HAD or rosette formation. Rosette formation was observed daily by an inverted microscope for 4-5 days. After four freeze-thaw cycles, the supernatants were assessed for the ASFV virus by real-time polymerase chain reaction (PCR) using the OIE manual's recommendations described by Jürgen et al. [20].

\section{Results}

\section{The active ingredient NOBF}

The gas chromatography technique measures the active ingredients present in the blended oil. By comparing with chromatographs of pure standards,
$\mathrm{GC}$ analysis identified the presence of antiviral compounds, namely, (A) cineole, (B) linalool, and (C) isobornyl acetate in the NOBF (Figure-2). The result shows that cineole was present at a retention time of $3.048 \mathrm{~min}$ with a relative percentage area of peak around $99.4 \%$, making it the primary compound in the NOBF. The second compound identified is linalool at a retention time of $5.966 \mathrm{~min}$ and a relative percentage peak around $0.31 \%$. The minor compound identified is isobornyl acetate at a retention time of 3.767 and a relative percentage area of peak around $0.28 \%$ (Table-2).

\section{Toxicity test and efficacy of NOBF in PAMs culture against ASFV}

The toxicity of the NOBF in PAMs cultures was tested in PAM cells along with the trial. PAM cell death was recorded up to dilution six at $36 \mathrm{~h}$ of observation. Cell death occurred in dilution seven wells at $48 \mathrm{~h}$ and dilution eight at $72 \mathrm{~h}$ of culture. No PAM cells died in dilution nine and onward until the last observation at $120 \mathrm{~h}$. The obtained results show that the NOBF in dilutions 1-6, that is, up to $0.08 \mathrm{~mL}$, inhibited the growth of PAM cells (Figures-3 and 4).

Table-1: Natural oil blend formulation (NOBF) mixed with RPMI and African swine fever virus (ASFV) in serial fold 2 dilution.

\begin{tabular}{lccccc}
\hline Dilution & $\begin{array}{c}\text { ASF } \\
\text { Virus } \\
(\mathbf{m L})\end{array}$ & $\begin{array}{c}\text { NOBF } \\
(\mathbf{m L})\end{array}$ & $\begin{array}{c}\text { RPMI } \\
(\mathbf{m L})\end{array}$ & $\begin{array}{c}\text { NOBF } \\
(\mathbf{\%})\end{array}$ & $\begin{array}{c}\text { NOBF } \\
(\mathbf{p p m})\end{array}$ \\
\hline 1 & 5 & 2.5 & 2.5 & 25 & 250,000 \\
2 & 5 & 1.25 & 3.75 & 13 & 125000 \\
3 & 5 & 0.625 & 4.375 & 6.30 & 62500 \\
4 & 5 & 0.3125 & 4.6875 & 3.10 & 31250 \\
5 & 5 & 0.156 & 4.998 & 1.56 & 15600 \\
6 & 5 & 0.08 & 4.92 & 0.80 & 8000 \\
7 & 5 & 0.04 & 4.96 & 0.40 & 4000 \\
8 & 5 & 0.02 & 4.98 & 0.20 & 2000 \\
9 & 5 & 0.01 & 4.99 & 0.10 & 1000 \\
10 & 5 & 0.005 & 4.995 & 0.05 & 500 \\
11 & 5 & 0.0025 & 4.9975 & 0.03 & 250 \\
12 & 5 & 0.00125 & 4.99875 & 0.01 & 125 \\
13 & 5 & 0.000625 & 4.999375 & 0.01 & 62.5 \\
14 & 5 & 0.000312 & 4.999688 & 0.00 & 31.25 \\
15 & 5 & 0.000156 & 4.999844 & 0.00 & 15.625 \\
16 & 5 & 0.000078 & 4.999921 & 0.00 & 7.812 \\
Positive & 5 & - & 5 & - & - \\
Control & & & & & \\
Negative & $($ buffer & - & 5 & - & - \\
Control & $5 \mathrm{ml})$ & & & & \\
\hline
\end{tabular}

The $5 \mathrm{~mL}$ of VNUA-ASFV-L01/HN/05/19 mixed in each tube except negative control. The NOBF was serially 2 -fold diluted up to $7.8 \mathrm{ppm}$. NOBF=Natural oil blend formulation

Table-2: Gas chromatography-flame ionization detector chromatogram of natural oil blend formulation in tabular form with complete details of measurement and analysis.

\begin{tabular}{|c|c|c|c|c|c|c|c|c|c|}
\hline Peak No. & Name & Ret. time & Area & Height & HETP & Resolution & Tailing factor & $\mathbf{k}^{\prime}$ & Separation \\
\hline 1 & Cineole & 3.048 & 3516085 & 11587085 & 0.000 & 0.000 & 0.831 & 0.000 & 0.000 \\
\hline 2 & Linalool & 5.966 & 11108 & 4328 & 0.000 & 12.943 & 0.840 & 0.236 & 0.000 \\
\hline 3 & Isobornyl acetate & 3.767 & 10037 & 2854 & 0.000 & 30.333 & 0.000 & 0.957 & 4.057 \\
\hline Total & & & 3537230 & 11594267 & & & & & \\
\hline
\end{tabular}




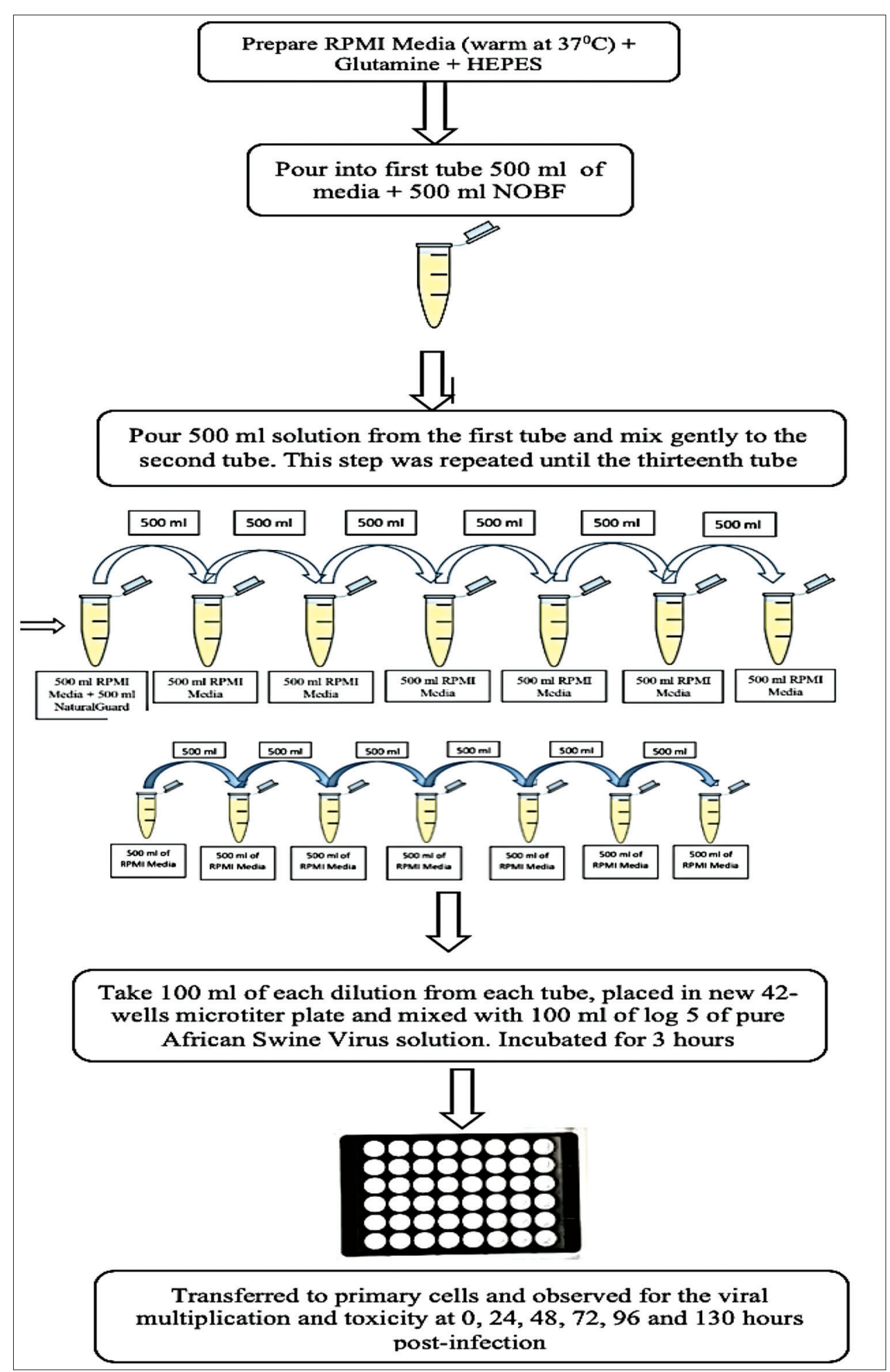

Figure-1: Diagrammatic illustration of in vitro trial steps preparation. RPMI media, natural oil blend formulation, and African swine fever virus prepared and mixed using 2 -fold dilution method. No virus was mixed in negative control. Microscopic observation was made at 0 h, 24 h, 48 h, 72 h, 96 h, and $130 \mathrm{~h}$ intervals.

The detailed stepwise observation at $96 \mathrm{~h}$ post-infection occurred as follows:

In vitro observation showed that the NOBF up to dilution 13 or $0.000625 \mathrm{~mL}$ could inhibit or degenerate ASFV at a titer of $10^{5}$ HAD50 in the PAMs culture (Table-1). No HAD or rosette was observed up to $130 \mathrm{~h}$ post-infection (Figure-3 and 4) whereas positive controls showed a large number of rosettes formation.

\section{Real-time PCR analysis of in vitro trial}

After four freeze-thaw cycles of PAMs, the supernatants were collected and applied for total DNA extraction, then used for real-time PCR [20]. The real-time PCR results (Ct value) indicated that the virulent ASFV strain could not replicate or was denatured in the PAMs cultures (Table-3). No difference in Ct value obtained in the initial ASFV input control compared to the natural oil blend group at 
dilutions 10,11 , and 12 after $130 \mathrm{~h}$ post-infection in PAMs (Table-3). Remarkably, the difference in the natural oil blend group's Ct value was statistically significant compared with the ASFV-positive control group (Table-3).

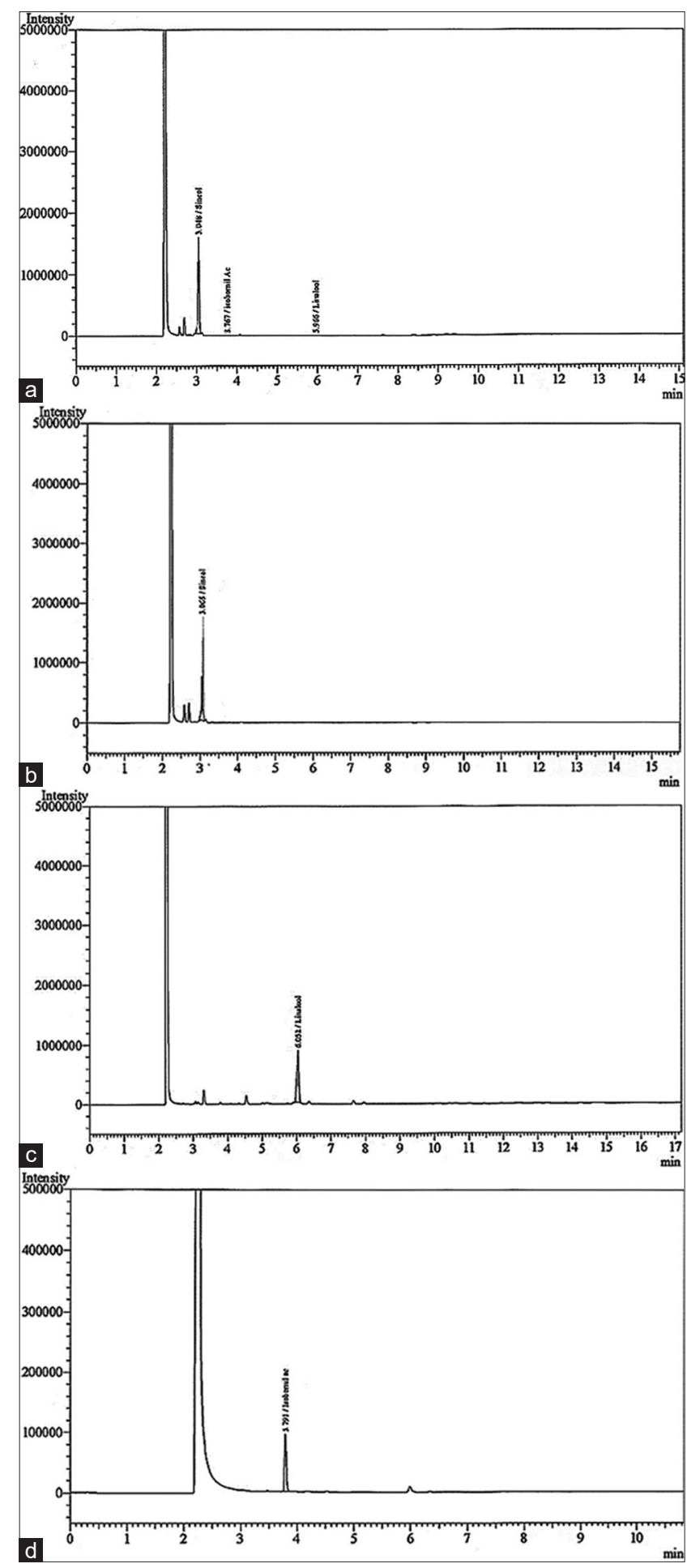

Figure-2: Gas chromatography-flame ionization detector chromatogram of natural oil blend formulation (NOBF). (a) Chromatogram of complete NOBF compound's peak, that is, cineole, linalool, and isobornyl acetate, (b) Chromatogram of cineole from NOBF, (c) chromatogram of linalool from NOBF, and (d) chromatogram of isobornyl acetate from NOBF.

\section{Discussion}

African swine fever is a highly contagious fatal acute hemorrhagic viral disease of pigs that currently have no treatment or vaccination protocol. It threatens the pig industry worldwide. For farmers, managing recent outbreaks of infectious viral diseases remain a significant worldwide problem, and there is a need to find substances with intracellular and extracellular antiviral properties [21-26]. The ASFV precisely activates the Ataxia Telangiectasia Mutated Rad3-related (ATR) pathway in ASFV-infected swine monocyte-derived macrophages (MDMs) in the early phase of infection, most probably because the ASFV genome is recognized as foreign DNA [27]. They also detected morphological changes of promyelocytic leukemia nuclear bodies, nuclear speckles, and Cajal bodies found in ASFV-infected swine MDMS. It suggests the process of viral modulation of cellular antiviral responses and cellular transcription. It was demonstrated that in vitro inhibition of ASFV-topoisomerase II disrupts viral replications, contributing to natural strategies for vaccine candidate development [28].

The in vitro level trials using the NOBF were conducted to evaluate its efficacy against ASFV. The natural oil blend had antiviral properties and deactivated the virus [29-31]. The antiviral activity of all the natural oils tested could be demonstrated for the enveloped viruses. Lavender natural oil consists primarily of monoterpenoids and sesquiterpenoids and linalool dominate, with moderate levels of lavandulyl acetate, terpinen-4-ol, and lavandulol. 1,8-cineole and camphor are also present in low to moderate qualities. Linalol has anti-microbial, anti-inflammatory, and mood alleviating effects [3234]. Pine oil consists mainly of alpha-terpineol or cyclic terpene alcohols and isobornyl acetate. Pine oil is a phenolic disinfectant that is mildly antiseptic and has anti-fungal, antibacterial, and antiviral properties due to isobornyl acetate [33,34]. Eucalyptus oil has a history of full application as a pharmaceutical, antiseptic, repellent, flavoring, fragrance, and industrial use. Eucalyptus oil has antibacterial, antiviral, and anti-inflammatory effects. The pre-clinical results also show that eucalyptus oil stimulates the innate cell-mediated immune response by its effects on the phagocytic ability of human MDMs [31-37]. Cineole present in eucalyptus oil shows potential antiviral activity against herpesvirus and yellow fever virus. Its activity has also been established against viral envelope structures [34,35]. The natural oils affect the viral envelope, which is necessary for adsorption or entry into host cells. In particular, monoterpenes have shown increased cell membrane fluidity and permeability, altering membrane proteins' order [38-41].

The quantity $\log 5$ of the VNUA-ASFV-L01/ $\mathrm{HN} / 04 / 19$ virus strain ASFV is considered the lethal dose that can kill the pigs in 7-10 days intramuscular 
Table-3: Real-time PCR quantification of ASFV replication in treatment groups in vitro.

\begin{tabular}{llccc}
\hline No. & Groups & Dilution & \multicolumn{2}{c}{ HAD $/$ real-time PCR } \\
\cline { 3 - 4 } & & 10 & Rosetta formation & Real-time PCR Ct value (mean) \\
\hline 1 & Group 1: Natural oil blend formulation & 11 & No & 25.96 \\
2 & & 12 & No & 25.89 \\
3 & & 13 & No & 25.16 \\
4 & & & Yes & 23.97 \\
5 & Group 2: Positive control & No & NA \\
6 & Group 3: Negative control & & & 25.74 \\
7 & Input control of ASFV $\alpha$ & & & \\
\hline
\end{tabular}

${ }^{\alpha}$ Initial ASFV dose that is used to apply all groups except negative control group. African swine fever virus. ASFV=African swine fever virus, $P C R=$ Polymerase chain reaction

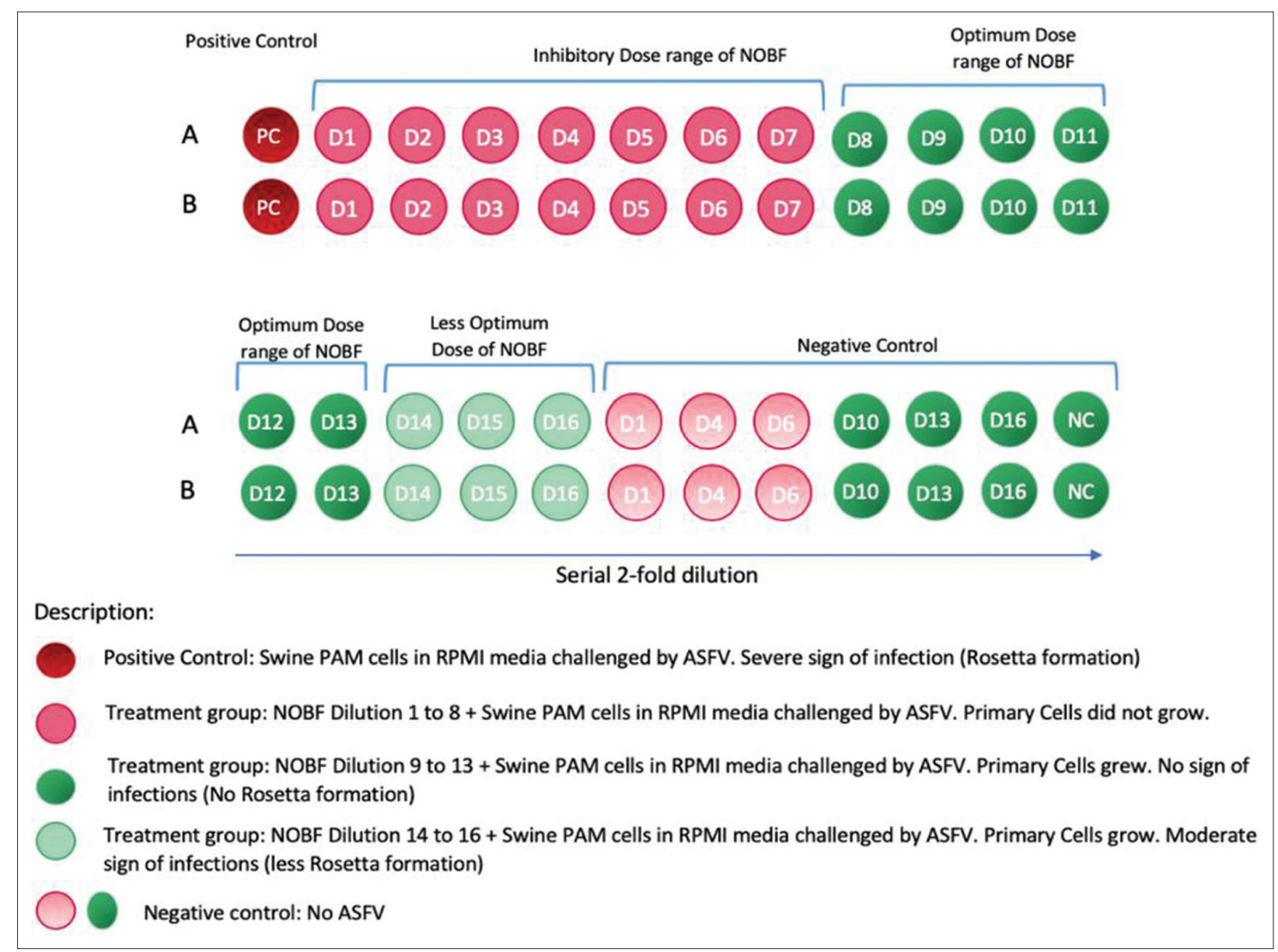

Figure-3: The illustration shows the result outcome of in vitro test. The inhibitory dose of the natural oil blend formulation (NOBF) was observed from dilution 1-7. The optimum and effective dose of NOBF against African swine fever virus (ASFV) was observed from dilutions 8-13. The less effective dose started from dilutions 14. The different dilutions of negative control (without ASFV) indicated the inhibitory and not-inhibitory doses of NOBF on porcine alveolar macrophages cells.

challenge. The evaluation of in vitro antiviral activities of natural substances is based mainly on the inhibition of cytopathic effects, the reduction or inhibition of plaque formation, and the reduction in the virus yield [21].

The PAM cells were isolated from the pathogen-free clean piglets. The characteristic feature of the cells infected with ASFV wildtype is the ability to adsorb swine erythrocytes (haemadsorption - HAD) on its surface [40]. This feature was successfully exploited to differentiate the ASF virus from other agents that produce diseases with symptoms that are likely to be confused with those observed in ASF and develop specific ASF virus titration [42]. Erythrocyte rosettes formation around infected blood swine monocytes is a characteristic feature of ASFV-infected cells $[43,44]$. It is considered the standard HAD test for many ASFV isolates

The real-time PCR results showed no growth of the virus in the NOBF groups indicated from the similar $\mathrm{Ct}$ value. In comparison, the $\mathrm{Ct}$ value of positive control reduced, which indicated the spontaneous increase in viral copy number [20].

The obtained results showed the way in the process of anti-ASFV component development. Hence, the anti-ASFV developed components, either live-attenuated vaccine or recombinant vaccine, have 


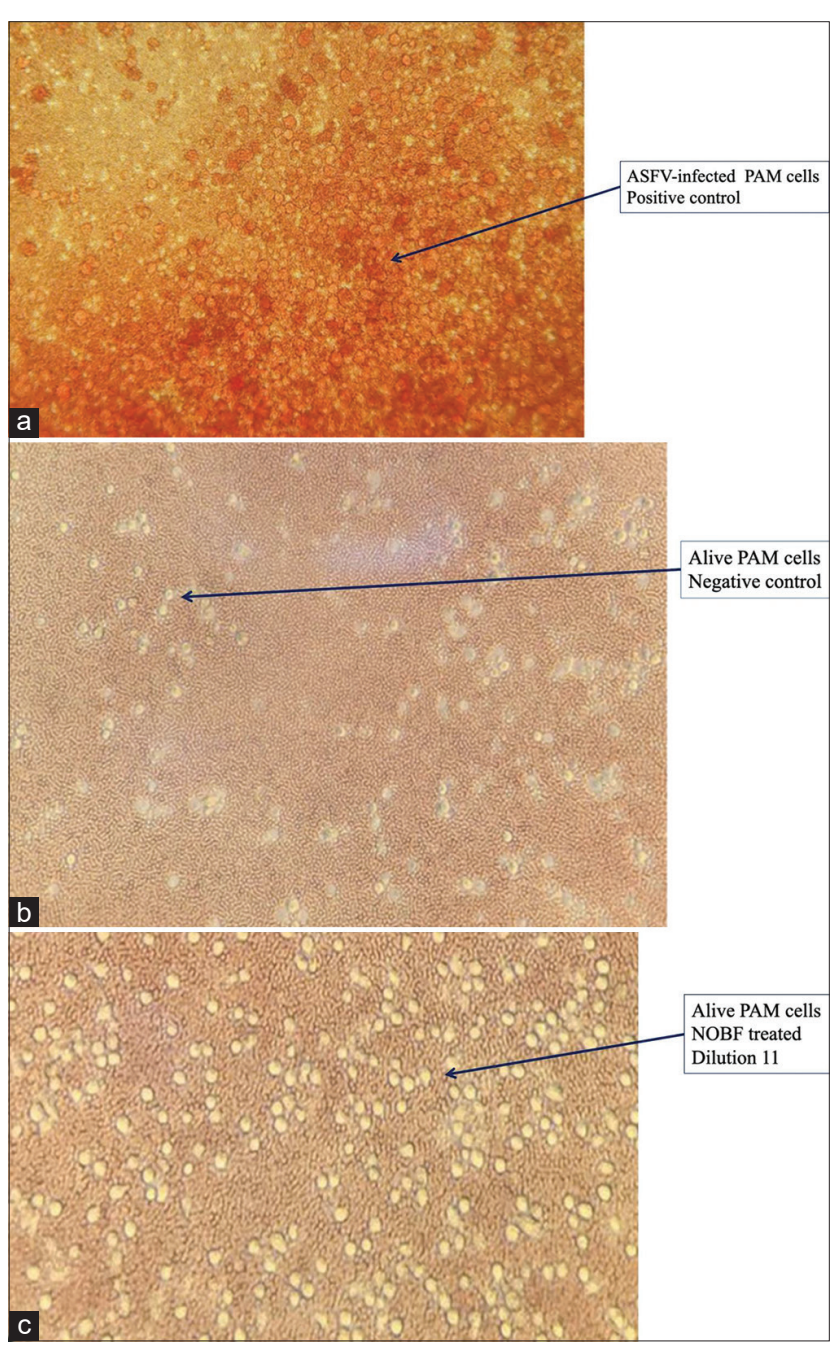

Figure-4: (a) Representative microscopic images of positive control, that is, porcine alveolar macrophages (PAMs) cells inoculated with African swine fever virus. (b) Representative microscopic images of negative control, that is, PAM cells not inoculated with African swine fever virus. (c) Representative microscopic images of PAM cells inoculated with African swine fever virus treated in dilution 11 or $250 \mathrm{ppm}$ of natural oil blend formulation for $130 \mathrm{~h}$. (c) Images were taken on Leica DM IL LED microscope at $200 \times$

not shown efficacy in the field [45-49]. The immediate next step would be to evaluate and optimize the efficacy of NOBF against ASFV in the pig.

\section{Conclusion}

The present study highlights the role of natural oil extracts in virus eradication. In this study, we try to demonstrate that the NOBF can degenerate the ASFV in PAM cells medium. The trial outcome is summarized in the following way: The NOBF application deactivated the ASF virus at the lowest concentration of $0.000635 \mathrm{~mL}$. As a continuation of the study, the next step is to conduct in vivo trials to optimize the dose and delivery route of the NOBF and to establish it as an anti-ASFV candidate.

\section{Authors' Contributions}

QLT, HYB, and RKJ contributed to the study conception. HTN contributed to sample analysis.
QLT, HYB, and RKJ designed and conducted the experiments. QLT, HYB, and RKJ analyzed the data. HYB and RKJ drafted the manuscript. LTN and TLT edited the manuscript. All authors read and approved the final manuscript.

\section{Acknowledgments}

Financial assistance from the PT. Central Proteina Prima, Indonesia, as part of the research and development program, is duly acknowledged. The authors are thankful to the Centre for Research in Agriculture and Fisheries (CeRAF), Vietnam, Vietnam National University of Agriculture, Vietnam and PT. Rhea Natural Sciences, Indonesia, for providing the infrastructural facilities to conduct the trials.

\section{Competing Interests}

The authors declare that they have no competing interests. The authors did not receive any funds from PT. Central Proteina Prima.

\section{Publisher's Note}

Veterinary World remains neutral with regard to jurisdictional claims in published institutional affiliation.

\section{References}

1. Rowlands, R.J., Michaud, V., Heath, L., Hutchings, G., Oura, C., Vosloo, W., Dwarka, R., Onashvili, T., Albina, E. and Dixon, L.K. (2008) African swine fever virus isolate, Georgia, 2007. Emerg. Infect. Dis., 14(12): 1870-1874.

2. Penrith, M.L., Vosloo, W., Jori, F. and Bastos, A.D.S. (2013) African swine fever virus eradication in Africa. Virus Res., 173: 228-246.

3. Halasa, T., Bøtner, A., Mortensen, S., Christensen, H., Toft, N. and Boklund, A. (2016) Simulating the epidemiological and economic effects of an African swine fever epidemic in industrialized swine populations. Vet. Microbiol., 193:

4. Sánchez-Cordón, P.J., Montoya, M., Reis, A.L. and Dixon, L.K. (2018) African swine fever: A re-emerging viral disease threatening the global pig industry. Vet. J., 233: 41-48.

5. World Organization for Animal Health. (2019) Terrestrial Animal Health Code. World Organization for Animal, Paris.

6. World Organization for Animal Health. (2019) Manual of Diagnostic Tests and Vaccines for Terrestrial Animals. World Organization for Animal Health, Paris.

7. World Organisation for Animal Health. (2020b) Available from: https://www.oie.int/wahis_2/public/wahid.php/ reviewreport/review?page_refer=mapfulleven-treport\&reportid $=34283$. Retrieved on 19-10-2020.

8. World Organization for Animal Health. (2020a) African Swine Fever (ASF) Report No. 52: August 21-September 03, 2020. World Animal Health Information Department, World Organization for Animal Health, Paris, France.

9. Jassim S.A. and Naji M.A. (2003) Novel antiviral agents: A medicinal plant perspective. J. Appl. Microbiol., 95(3): 412-427.

10. Food and Agriculture Organization. (2018) African Swine Fever Threatens Peoples Republic of China. Animal Health Risk Analysis, Assessment No. 5. Food and Agriculture Organization, Rome, Italy.

11. Juergens, U. (2014) Anti-inflammatory properties of the monoterpene 1.8-cineole: Current evidence for co-medication in inflammatory airway diseases. Drug Res., 64(12): 
638-646.

12. Wang, L.H., Madera, R., Li, Y.Z., McVey, S.D., Drolet, B.S. and Shi, J. (2020) Recent advances in the diagnosis of classical swine fever and future perspectives. Pathogens, 9(8): 658.

13. Li, X.D., Zhang, C., Qiao, M.M., Guo, J.S., Xing, G.Y., Jin, C.X., Wang, J., Sun, M. and Tian, K. (2018) Molecular epidemiology of porcine circovirus Type 3 infection in swine herds in China. Virol. Sin., 33(4): 373-377.

14. Choi, H.J. (2018) Chemical constituents of essential oils possessing anti-influenza A/WS/33 virus activity. Osong Public Health Res. Perspect., 9(6): 348-353.

15. Takizawa, T., Nakashima, K., Namihira, M., Ochiai, W., Uemura, A., Yanagisawa, M., Fujita, N., Nakao, M. and Taga, T. (2001) DNA methylation is a critical cell-intrinsic determinant of astrocyte differentiation in the fetal brain. Dev. Cell, 1(6): 749-758.

16. Chenais, E., Ståhl, K., Guberti, V. and Depner, K. (2018) Identification of wild boar-habitat epidemiologic cycle in African swine fever epizootic. Emerg. Infect. Dis., 24(4): 810.

17. Probst, C., Gethmann, J., Amler, S., Globig, A., Knoll, B. and Conraths, F.J. (2019) The potential role of scavengers in spreading African swine fever among wild boar. Sci. Rep., 9(1): 11450

18. Reed, L.J. and Muench, H.A. (1938) Simple method of estimating fifty percent endpoints. Am. J. Hyg., 27(3): 493-497.

19. King, D.P., Reid, S.M., Hutchings, G.H., Grierson, S.S., Wilkinson, P.J., Dixon, L.K., Bastos, A.D.S. and Drew, T.W. (2003) Development of a TaqMan ${ }^{\circledR}$ PCR assay with internal amplification control for the detection of African swine fever virus. J. Virol. Methods, 107(1): 53-61.

20. Jürgen, R., Schnitzler, P., Suschke, U. and Saller, R. (2009) Essential oils of aromatic plants with antibacterial, antifungal, antiviral, and cytotoxic properties an overview. Forsch. Komplement. Med., 16(2): 79-90.

21. Simoes, M., Martins, C. and Ferreira, F. (2015) Early intranuclear replication of African swine fever virus genome modifies the landscape of the host cell nucleus. Virus Res., 210: 1-356.

22. Chenais, E., Boqvist, S., Sternberg-Lewerin, S., Emanuelson, U., Ouma, E., Dione, M., Aliro, T., Crafoord, F., Masembe, C. and Stahl, K. (2017a) Knowledge, attitudes and practices related to African swine fever within smallholder pig production in Northern Uganda. Transbound. Emerg. Dis., 64(1): 101-115.

23. Chenais, E., Boqvist, S., Emanuelson, U., von Bromssen, C., Ouma, E., Aliro, T., Masembe, C., Stahl, K. and SternbergLewerin, S. (2017b) Quantitative assessment of social and economic impact of African swine fever outbreaks in Northern Uganda. Prev. Vet. Med., 144(1): 134-148.

24. Beltrán-Alcrudo, D., Arias, M., Gallardo, C., Kramer, S. and Penrith, M.L. (2017) African Swine Fever: Detection and Diagnosis a Manual for Veterinarians. FAO Animal Production and Health Manual No. 19. Food and Agriculture Organization of the United Nations, Rome. p88.

25. Depner, K., Gortazar, C., Guberti, V., Masiulis, M., More, S. and Oḷ̌sevskis, E. (2017) Epidemiological analyses of African swine fever in the Baltic states and Poland. EFSA $J ., 15(11): 5068$.

26. Cappai, S., Rolesu, S., Coccollone, A, Laddomada, A. and Loi, F. (2018) Evaluation of biological and socio-economic factors related to persistence of African swine fever in Sardinia. Prev. Vet. Med., 152(1): 1-11.

27. Simoes, M., Ferreira, F.B., Leitao, A., Martins, C. and Ferreira, F. (2019) African swine fever virus replication events and cell nucleus: New insights and perspectives. Virus Res., 270: 197667.

28. Gostner, J.M., Ganzera, M., Becker, K., Geisler, S., Schroecksnadel, S., Überall, F., Schennach, H. and Fuchs, D. (2014). Lavender oil suppresses indoleamine 2,3-dioxygenase activity in human PBMC. BMC Complement. Altern. Med., 14: 503.
29. Shellie, R., Mondello, L., Philip, M. and Giovanni, D. (2002) Characterization of lavender essential oils by using gas chromatography-mass spectrometry with correlation of linear retention indices and comparison with comprehensive two-dimensional gas chromatography. J. Chromatogr. A, 970(1-2): 225-234

30. Juergens, U.R., Dethlefsen, U., Steinkamp, G., Gillissen, A., Repges, R. and Vetter, H. (2003) Anti-inflammatory activity of 1.8-cineol (eucalyptol) in bronchial asthma: A double-blind placebo-controlled trial. Respir. Med., 97(3): 250-256.

31. Juergens, U.R., Engelen, T., Racké, K., Stöber, M., Gillissen, A. and Vetter, H. (2004) Inhibitory activity of 1,8-cineol (eucalyptol) on cytokine production in cultured human lymphocytes and monocytes. Pulm. Pharmacol. Ther., 17(5): 281-287.

32. Serafino, A., Vallebona, P.S., Andreola, F., Zonfrillo, M., Mercuri, L., Federici, M., Rasi, G., Garaci, E. and Pierimarchi, P. (2008) Stimulatory effect of Eucalyptus essential oil on innate cell-mediated immune response. BMC Immunol., 9: 17.

33. Göbel, H., Schmidt, G. and Soyka, D. (1994) Effect of peppermint and Eucalyptus oil preparations on neurophysiological and experimental algesimetric headache parameters. Cephalalgia, 14(3): 228-234.

34. Astani, A., Reichling, J. and Schnitzler, P. (2010) Comparative study on the antiviral activity of selected monoterpenes derived from essential oils. Phytother. Res., 24(5): 673-679.

35. Karger, A., Pérez-Núñez, D., Urquiza, J., Hinojar, P., Alonso, C., Freitas, F.B., Revilla, Y., Le Potier, M.F. and Montoya, M. (2019) An update on african swine fever virology. Viruses, 8(9): 864-878.

36. Yoo, D., Kim, H., Lee, J.Y. and Yoo, H.S. (2020) African swine fever: Etiology, epidemiological status in Korea, and perspective on control. J. Vet. Sci., 21(2): 38.

37. Salguero, F.J. (2020) Comparative pathology and pathogenesis of African swine fever infection in swine. Front. Vet. Sci., 19(7): 282-295.

38. Hess, W.R., Endris, R.G., Haslett, T.M., Monahan, M.J. and McCoy, J.P. (1987) Potential arthropod vectors of African swine fever virus in North America and the Caribbean basin. Vet. Parasitol., 26(1-2): 145-155.

39. do, I. and Alonso, C. (2017) African swine fever virus: A review. Viruses, 9(5): 103

40. Gallardo, C., Fernández-Pinero, J. and Arias, M. (2019) African swine fever (ASF) diagnosis, an essential tool in the epidemiological investigation. Virus Res., 271(10): 197676.

41. Dixon, L.K., Islam, M., Nash, R. and Reis, A.L. (2019) African swine fever virus evasion of host defences. Virus Res., 266(1): 25-33.

42. Juszkiewicz, M., Walczak, M., Mazur-Panasiuk, N. and Woźniakowski, G. (2019) Virucidal effect of chosen disinfectants against African swine fever virus (ASFV) preliminary studies. Pol. J. Vet. Sci., 22(4): 777-780.

43. Kouam, M.K., Jacouba, M. and Moussala, J.O. (2020) Management and biosecurity practices on pig farms in the Western Highlands of Cameroon (Central Africa). Vet. Med. Sci., 6(1): 82-91.

44. Revilla, Y., Perez-Nunez, D. and Richt, J.A. (2018) African swine fever virus biology and vaccine approaches. $A d v$. Virus Res., 100(1): 41-44.

45. Gallardo, C., Sánchez, E.G., Pérez-Núñez, D., Nogal, M., de León, P., Carrascosa, Á.L. and Revilla, Y. (2018a). African swine fever virus (ASFV) protection mediated by NH/P68 and NH/P68 recombinant live-attenuated viruses. Vaccine, 36(19): 2694-2704.

46. Reis, A.L., Abrams, C.C., Goatley, L.C., Netherton, C., Chapman, D.G., Sanchez-Cordon, P. and Dixon, L.K. (2016). Deletion of African swine fever virus interferon inhibitors from the genome of a virulent isolate reduces virulence in domestic pigs and induces a protective response. 
Vaccine, 34(39): 4698-4705.

47. Reis, A.L., Goatley, L.C., Jabbar, T., Pedro, J., SanchezCordon, P.J., Christopher, L. and Dixon, L.K. (2017b) Deletion of the African swine fever virus gene DP148R does not reduce virus replication in culture but reduces virus virulence in pigs and induces high levels of protection against challenge. J. Virol., 91(24): e01428-17.

48. Sánchez-Cordón, P.J., Jabbar, T., Berrezaie, M., Chapman, D., Reis, A., Sastre, P. and Dixon, L.K. (2018b)
Evaluation of protection induced by immunisation of domestic pigs with deletion mutant African swine fever virus Benin $\triangle \mathrm{MGF}$ by different doses and routes. Vaccine, 36(5): 707-715.

49. Gallardo, C., Soler, A., Rodze, L., Nieto, R., CanoGómez, C., Jovita Fernandez-Pinero, J. and Arias, M. (2018b). Attenuated and non-haemadsorbing (non-HAD) genotype II African swine fever virus (ASFV) isolated in Europe, Latvia 2017. Trans. Emerg. Dis., 66(3):1399-1404. 